\title{
Distance Learning for Continuing Education - What Engineers Want
}

\author{
Eugene Rutz \\ University of Cincinnati
}

\begin{abstract}
An educational needs assessment was distributed to practicing engineers to evaluate interest in continuing education offered through distance learning technologies. Responses to the assessment indicated preferences of practicing engineers for programs related to engineering management, computer science and engineering, and mechanical / manufacturing engineering. The assessment also indicated that engineers prefer technologies that are computer-mediated.

\section{Introduction}

The need for continuing education of practicing engineers has been documented and the barriers to wide spread participation in programs has been identified ${ }^{1,2}$. Many educational institutions see distance learning technologies and teaching strategies playing a significant role in overcoming barriers to participation ${ }^{3}$. To help quantify practicing engineers' interest in continuing education offered through distance learning, an educational needs assessment was developed and distributed to approximately 1,000 engineers. The assessment evaluated: learner characteristics and resources, content areas, preferences for distance learning delivery technology, importance of credit-granting programs, and acceptance of distance learning.
\end{abstract}

\section{What We Learned}

$60 \%$ of the engineers responding to the assessment indicated high or moderate interest in participating in continuing education over the next three years. $47 \%$ had participated in continuing education or graduate study in the past three years. The responses indicated that $95 \%$ of this population have access to a "Pentium PC" or equivalent and $88 \%$ had Internet access.

The survey asked individuals to indicate interest (none, slight, moderate, or high) in seventeen distinct content areas. The responses were filtered to only include those individuals with high or moderate interest in professional development programs over the next three years. This data was then analyzed to determine the most requested content areas. These are shown in Table 1.

$\begin{array}{lc}\begin{array}{c}\text { Table } 1 \text { Content Areas of Interest } \\ \text { Area }\end{array} & \begin{array}{c}\text { Interest } \\ \text { Engineering Management }\end{array} \\ 62 \% \\ \text { Computer Engineering } & 41 \% \\ \text { Computer Science } & 40 \% \\ \text { Mechanical Engineering } & 35 \% \\ \text { Manufacturing Engineering } & 34 \%\end{array}$


Continuing education can take several forms including formal graduate coursework and noncredit professional development programs. The needs assessment sought to quantify interest in various options. Responses are shown in Table 2. As with other survey questions, an individual's response was not limited to one type of program, therefore total percentages indicated in the table are greater than $100 \%$.

\begin{tabular}{lc}
\multicolumn{2}{c}{ Table 2 Program Preferences } \\
Program & Interest \\
Non-Credit Professional Development & $88 \%$ \\
Individual Course for Credit & $59 \%$ \\
MS Degree & $45 \%$ \\
Graduate Certificate (for credit) & $43 \%$ \\
PhD Degree & $18 \%$
\end{tabular}

Universities use a variety of technologies to deliver courses via distance learning. The needs assessment measured interest in a number of these technologies. Table 3 lists the preferences indicated for distance learning technologies.

$\begin{array}{lc}\begin{array}{l}\text { Table 3 Technology Preferences } \\ \text { Technology }\end{array} & \begin{array}{c}\text { Interest } \\ \text { Internet }\end{array} \\ \text { CD ROM } & 92 \% \\ \text { Videotape } & 76 \% \\ \text { 2-way Video } & 62 \% \\ \text { Audio + Computer } & 59 \% \\ \text { Satellite } & 50 \% \\ \text { Two Way Audio } & 38 \%\end{array}$

The nature of distance education is such that the instructor and students are physically separated possibly resulting in barriers to effective interaction ${ }^{4,5}$. The needs assessment provided a qualitative evaluation of the relative importance of various factors germane to distance learning. Table 4 lists factors that deserve special consideration in delivering continuing education through distance learning.

\section{Table 4 Distance Learning Factors}

\section{Very Important}

Flexible course and program time and location

Scheduled opportunities for interaction with instructors

Flexible completion time

Technical support

\section{Not Important}

Interaction with other students during course presentation

Interaction with instructor during course presentation

Traditional university calendar 
This table illustrates that while it was very important to have scheduled opportunities to interact with the instructor the practicing engineers did not feel this interaction needed to coincide with the class presentation.

\section{Changing the Culture in Engineering Education}

To have effective continuing education programs, engineering colleges will have to be responsive to the needs of practicing engineers both in content areas and delivery of the content ${ }^{6}$. Engineering colleges need to offer more non-credit professional development programs designed to provide pragmatic job skills as opposed to only offering graduate course work ${ }^{2}$. Based on results of the needs assessment, delivery via the Internet provides the greatest potential opportunity. Certain media-rich programs will likely require CD-ROM delivery until sufficient bandwidth is commonly available to support video or until new technologies emerge ${ }^{7,8}$.

Identifying content areas of interest is straightforward, however, recruiting faculty to participate in these programs is more of a challenge ${ }^{3}$. Presenting content via distance learning technologies is new to most instructors and developing materials to be presented via technology requires significant effort ${ }^{9,10}$. Once the presentation materials are in an appropriate (electronic) form however, these materials can be formatted and packaged for delivery via computer-mediated delivery or video-based delivery.

The needs assessment clearly demonstrated the desire of practicing engineers to have continuing education available without many of the constraints of the traditional university system. The study found that these potential students did not want to be constrained to the academic calendar, nor did they want to be constrained in time or place that a course is offered ${ }^{11,12}$. Colleges face a significant, internal change in culture to make programs available using a non-traditional educational structure. While it is appropriate to impose some constraints to encourage timely completion of a course, these constraints should not be those associated with the traditional oncampus students ${ }^{10}$.

Practicing engineers felt that scheduled interaction with the instructor was very important but not necessarily during the presentation of the course. Rather than interact with students during class, instructors can establish "virtual" office hours when they can be contacted via phone or email.

Technology allows instructors to collect email from students and provide a common response to all participating in the course. To encourage active participation, it is often necessary to purposefully design elements into the distance learning course that promote and prompt interaction $^{4,13}$.

The needs assessment highlighted the need for technology support for distance learners. This will be particularly important for courses delivered via computer-mediated technologies. Distance learners will need technical support in a variety of areas, including: email, Internet access, downloading computer files, software problems, access to resources, etc. Given the previously stated importance of anytime, anyplace access, this support will have to be available seven days a week, twenty-four hours a day. 


\section{Conclusions}

Practicing engineers need and desire continuing education that allows them to contribute to the technical workforce and to the success of their organizations. Engineering management and computer science are two areas of particularly significant interest. Well-designed distance learning programs, especially those that are delivered via computer-mediated technologies, provide the opportunity to increase the number of engineers participating in continuing education.

Bibliography

1. NRC, "Engineering Education and Practice in the US: Continuing Education of Engineers", National Academy Press, Washington, D.C. 1985.

2. NRC, "Engineering Education: Designing an Adaptive System", National Academy Press, Washington, D.C., 1995.

3. Sanoff, A.P., "Long Distance Relationship", in ASEE Prism, vol. 9, no. 1, September 1999, pp. 22-26.

4. Sherron, G.T., and Boettcher, J.V., "Distance Learning: The Shift to Interactivity", CAUSE Professional Paper Series, \#17, 1997.

5. The Institute for Higher Education Policy, "What's the Difference? A Review of Contemporary Research on the Effectiveness of Distance Learning in Higher Education", Washington, DC., 1999.

6. Matthews, D. "Transforming Higher Education", Educom Review, vol. 33, no. 5, 1998, pp. 48-57

7. Watson, B., (Microsoft Online Institute) Tricks \& Traps: Lessons the Microsoft Online Institute has Learned, presented at N.A. WEB 96 - The Second International North American Web Conference, October, 1998. URL http://www.uvm.edu/ hag/naweb96/zwatson.html

8. Auerbach, S. "Classroom in a Box", in Inside Technology Training, vol.2, no. 1, January 1998, pp. 38-42.

9. Wallace, D.R. and Mutooni, P., "A Comparative Evaluation of World Wide Web-Based and Classroom

Teaching", Journal of Engineering Education, vol. 87, no. 3, July 1997, pp. 211-219.

10. Petre, M., Carswell, L., Price, B., and Thomas, P. "Innovations in Large-Scale Supported Distance Teaching: Transformation for the Internet, Not Just Translation", Journal of Engineering Education, vol. 87, no. 4, October, 1998, pp.423-432.

11. Duchastel, D., "A Web Based Model for University Instruction", Journal of Educational Technology Systems, vol. 25, no. 3, 1997, pp. 221-228.

12. Butler, B. (Carnegie Mellon University), Continuous Education: A Model for WWW Based Education, URL http://www.umuc.edu/iuc/cmc96/papers/butler-p.html

13. Ostendorf, V.A., The Two-Way Video Classroom, Virginia Ostendorf, Inc. Littelton, CO, 1996, pp. 7-20.

\section{EUGENE RUTZ}

Eugene Rutz is Director of Engineering Professional Development and Distance Learning in the College of Engineering at the University of Cincinnati. Mr. Rutz is a registered Professional Engineer with experience in mechanical design, testing and analysis, project management and teaching. He received his B.S. in Nuclear Engineering in 1982 and an M.S. in Mechanical Engineering in 1987 from the University of Cincinnati. 